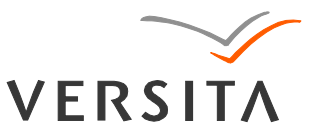

GEOCHRONOMETRIA 39(3) 2012: 227-232

DOI 10.2478/s13386-012-0006-4

Available online at

www.springerlink.com

\title{
INFRARED STIMULATED LUMINESCENCE (IRSL) PROPERTIES OF NATURAL ALUMINUM CORROSION
}

\author{
EREN ŞAHINER and NIYAZI MERIC \\ Ankara University, Faculty of Engineering, Department of Engineering Physics, \\ 06100, Tandoğan - Ankara, Turkey
}

Received 4 November 2011

Accepted 2 April 2012

\begin{abstract}
In this paper, the infrared stimulated luminescence (IRSL) property of naturally corroded aluminum and its possible applications in retrospective dosimetry have been briefly studied. Results are interesting, in particular with regard to the efforts of finding new and widely available materials for accident dosimetry. For aluminum corrosion, the dose response was found to be approximately linear between 2-80 Gy and to reach saturation before $300 \mathrm{~Gy}$. The signal also showed good reproducibility without significant fading over storage durations of up to four mounts at room temperature. In addition to the luminescence, the corrosion samples were also analysed by X-ray Fluorescence (XRF) and X-ray Diffraction (XRD), but conclusive identification of the luminescent phase could not be made. It is concluded that the IRSL signals of this material can be favourable for dosimetry research.
\end{abstract}

Keywords: dosimetry, luminescence, aluminum oxide, corrosion, IRSL

\section{INTRODUCTION}

Luminescence has been increasingly used for dosimetric purposes and its applications cover various fields, such as medical, environmental, personnel, and accident dosimetry, i.e. the retrospective assessment of doses received as a result of a nuclear accident (Botter-Jensen and Murray 2001; McKeever, 2001).

Comprehensive reviews and books describing the properties and use of luminescence dosimetric materials have been published (Bøtter-Jensen et al., 2003). However, there is continuing interest in developing new dosimetric materials, especially for the rapidly growing field of environmental radiation monitoring.

In the Optically Stimulated Luminescence (OSL) technique, light is used to stimulate the luminescence

Corresponding author: N. Meriç

e-mail: meric@ankara.edu.tr

ISSN 1897-1695 (online), 1733-8387 (print)

(C) 2012 Silesian University of Technology, Gliwice, Poland.

All rights reserved. from materials previously exposed to ionizing radiation, and the total luminescence emitted is proportional to the absorbed dose of radiation to which the material was exposed (Bøtter-Jensen et al., 2003). Some of the advantages offered by the OSL technique are associated with the all-optical readout process. That is to say, optical stimulation can be controlled more easily and in a more flexible way than heating, since the stimulation intensity can be continuous, pulsed, or ramped and the stimulation wavelength can be tuned to the properties of the material (Bøtter-Jensen et al., 2003). In addition, further advances in the OSL technique are likely since technological advances in LED and laser light sources, making them brighter, cheaper and more compact, have been rapid and are likely to continue (Yukihara et al., 2007).

Although OSL analysis is most commonly performed using green or blue stimulation wavelength, in certain materials stimulation by infrared photons also enables 
measurement of dose-dependent infrared-stimulated luminescence (IRSL). Because of its advantages, in this study the IRSL properties of natural corrosion products built up on aluminum are studied to investigate the possibility of its use in retrospective dosimetry.

For dosimetric purposes, synthetic dosimeters are generally used but may not be available at any given time and place. Therefore, for the determination of absorbed radiation doses, some generally available materials, such as bricks or porcelain and cementitious building materials can be used for assessment of radiation doses (Göksu et al., 2003). Göksu also has demonstrated that telephone chip-cards can be used as individual IRSL dosimeters (Göksu, 2003; Bøtter-Jensen et al., 2003).

Other dosimetric research has focused on biodosimetry applications. Biodosimetry is a method of measuring the amount of ionizing radiation dose received by individuals using biological materials. This type of dosimeter is useful when an individual is accidentally exposed and no dosimetric material is available. Yukihara et al. discussed optically stimulated luminescence properties of dental enamel (Yukihara et al., 2007). Meriç et al. investigated anthropological bone and teeth can be used in dosimetric studies using (Meriç et al. 2008; Yüce et al. 2010).

In this study, the dosimetric properties of naturally corroded aluminum-based building materials are examined. Many frequently used building materials, which contain quartz and feldspar minerals in their structure, have luminescence properties that make them suitable for use in environmental or retrospective dosimetry and these materials can contained various metal components in their structure. Interaction of these metals with air and water can cause corrosion of their surfaces over time.

Corrosion means chemical oxidation of metals in reaction with an oxidant such as oxygen. Stability of the oxides changes depending on the following environmental conditions that cause corrosion.

- The oxide is not stable in acidic $(\mathrm{pH}<4)$ or alkaline $(\mathrm{pH}>9)$ environments (Pourbaix, 1974).

- Certain elements (Ga, Tl, In, Sn, Pb) may become incorporated in the oxide and destabilize it (Nisancioglu, 1992).

During the corrosion process of metals the oxygen molecules in the air react with the surface of the metals. As a result, metal oxide compounds with complex structures are created which contain irregularities that may lead to the formation of luminescence centers. Thus the corroded material can display some luminescence properties.

In this study, the investigated corrosion samples were obtained from the inside of the corroded aluminum water pipes which did not exposure to the sun light that allows us to use OSL technique. The main advantage of the corrosion material is that the creation of that formation naturally happens in between building materials and thereafter acts like a recorder for the radiation doses.
Therefore, in case of accidental irradiation, corrosion material can be obtained from aluminum pipes and used to obtain the absorbed radiation dose.

\section{EXPERIMENTAL DETAILS}

The luminescence measurements were performed, using an Elsec 9010 Optical Dating System. The apparatus used was developed by Spooner et al. (Spooner et al., 1990). The system incorporates an IR LED (880 nm, FWHM $40 \mathrm{~nm}$ ) module based on the design described by Spooner et al. (Spooner et al., 1990). All data were collected using an IRSL add-on unit for the 9010 automated reader, which uses TEMT $484 \mathrm{IR}$ diodes run at $40 \mathrm{~mA}$, giving a power of about $30 \mathrm{~mW} / \mathrm{cm}^{2}$ at the sample.

Luminescence was detected using a Thorn EMI 9235 QA photomultiplier tube. The luminescence emission was measured using a Schott BG-39 glass filter. A ${ }^{90} \mathrm{Sr} /{ }^{90} \mathrm{Y} \beta$-ray source was used for irradiation and the typical dose rate is $0.029 \mathrm{~Gy} / \mathrm{s}$ on aluminum. The source was calibrated using facilities at the Secondary Standard Dosimetry Laboratory (SSDL) at GSF (Göksu et al., 1995).

The experimental steps are as follows:

- The material used in the study was a natural aluminum corrosion sample obtained from three aluminum water pipe pieces in the garden of the Ankara University, in Turkey. (Fig. 1)

- Samples were collected by scraping inner the pipe surfaces. These were initially gently crushed and sieved between 63-90 $\mu \mathrm{m}$. All samples were cleaned by distilled water and dried on incubator. No chemical treatments were applied on samples.

- Subsequently dried powder samples were deposited on aluminum discs of $1 \mathrm{~cm}^{2}$ area by using silicon spray. Before the measurements all discs were bleached on sun shine at five hours and carried out pre-read (100 seconds) for control residual signals. IRSL counts were recorded at room temperature after storage in a dark room for 24 hours.

- The luminescence properties of aluminum corrosion were studied on 27 discs, divided into groups of three

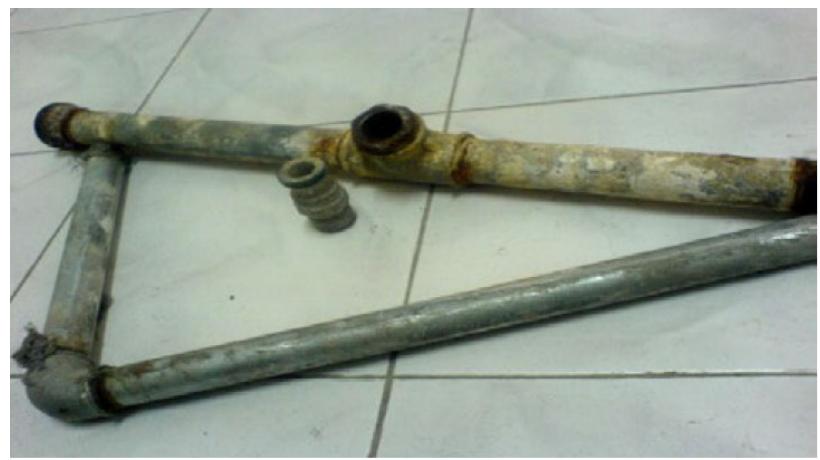

Fig. 1. Corroded aluminum pipes 
discs each. Additive dosing given to the groups were 2, 4, 8, 20, 40, 80, 300, 400, $500 \mathrm{~Gy}$.

- IRSL signals were collected under continuous wave (CW) stimulation and luminescence counts were plotted as a function of dose.

- For fading properties, another 15 discs were prepared and divided into groups of three discs. Each group was given a dose of $2 \mathrm{~Gy}$ and stored in the dark room for 1 week, 2 weeks, 1 month, 2 months and 4 months.

- Reproducibility of IRSL from aluminum corrosion was studied on three discs. Discs were read, directly after irradiation with a 2 Gy dose. Subsequently discs were bleached in sun-shine until all traps were emptied. These procedures were repeated 10 times for the same discs.

- Finally, the discs were weighed to determine normalization factors one by one. The average mass of the sample on a disc is approximately $8 \mathrm{mg}$. In order to calculate normalize IRSL counts normalization factors for each sample were multiplied their IRSL counts.

\section{RESULTS AND DISCUSSION}

Typical IRSL decay curves obtained at room temperature from aluminum corrosion are shown in Fig. 2 (A-B), respectively. It can be seen from Fig. 2 that the traps have been emptied completely in about $300 \mathrm{~s}$ and thus we studied only the 0-300 s integral of the IRSL results.

The IRSL dose response curves from materials are shown in Fig. 3 in which each point is the average of 3 discs, showing to be approximately linear between 2-80 Gy and to reach saturation before $300 \mathrm{~Gy}$. The fitting line of the graph is found to be between 2-80 Gy: $\mathrm{y}=0.91 \mathrm{x}+10.05$ and in all the dose range, IRSL emission shows a high intensity that means a good sensitivity, which is required from a good dosimetric material candidate. Sensitivity was determined as $\sim 2500$ counts $/ \mathrm{mg} / \mathrm{Gy}$ for this aluminum corrosion sample.

In order to characterize fading behavior, the IRSL curves after storage and the resulting fading curve are shown in Fig. 4 (A-B). Again in the graph every point is the average of 3 discs. According to the results, aluminum corrosion did not show significant fading during 4 months storage.
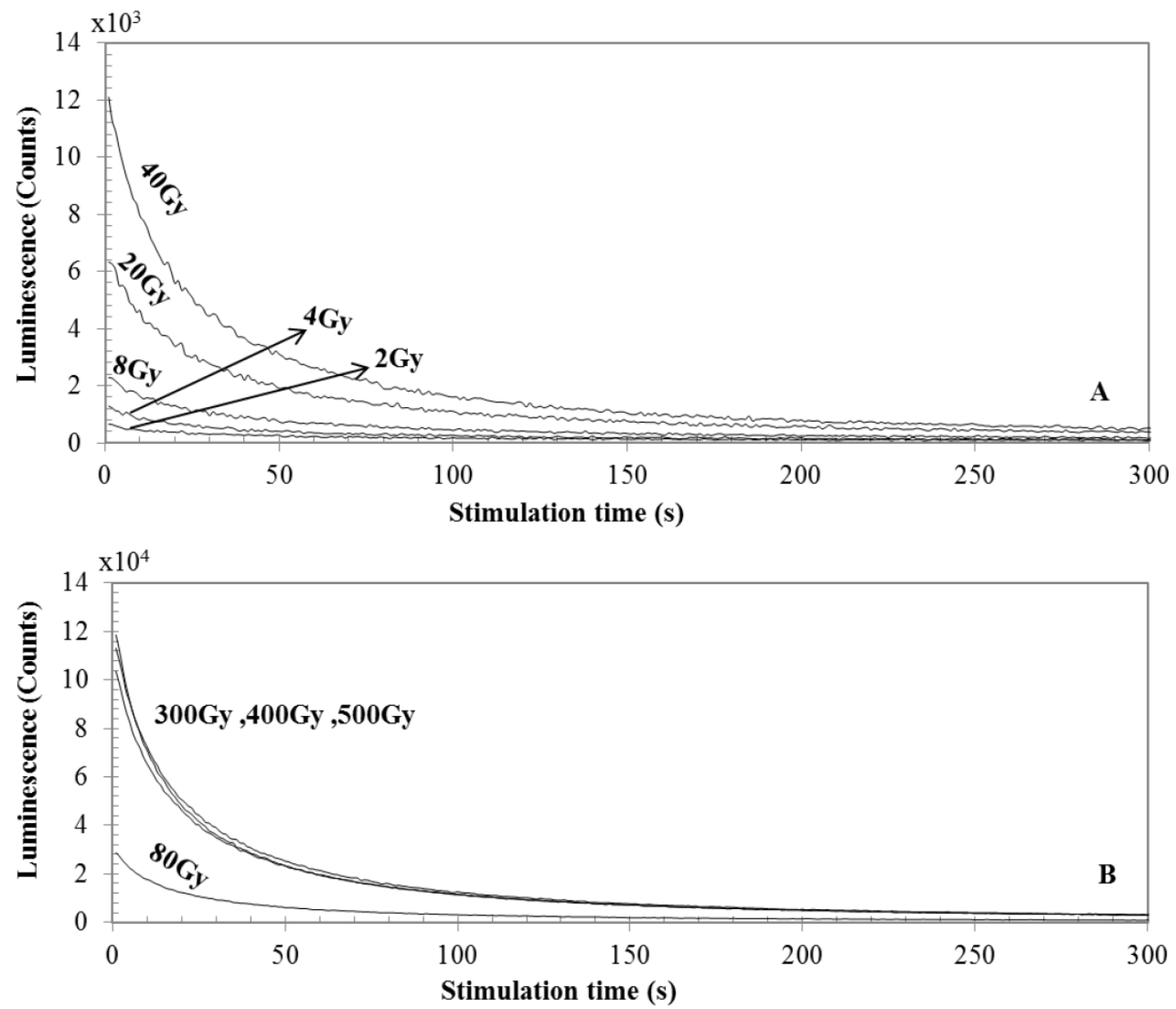

Fig. 2. Aluminum corrosion IRSL decay curves received from additive doses (a) 2-40 Gy, (b) 80-500 Gy 
On the other hand we investigated the reproducibility behavior. Fig. 5A shows the luminescence decay curves for 2 Gy beta dose and Fig. 5B is the integral of these signals for ten measurements. These data show that this material has a good reproducibility behavior for ten times.
Table 1 contains the X-ray fluorescence (XRF) analysis results of the natural aluminum corrosion. The corrosion structure contains a variety of elements that are known to give rise to luminescence. Particularly $\mathrm{Si}, \mathrm{Al}$, $\mathrm{K}, \mathrm{Na}, \mathrm{Ca}$ can affect the luminescence emission in the

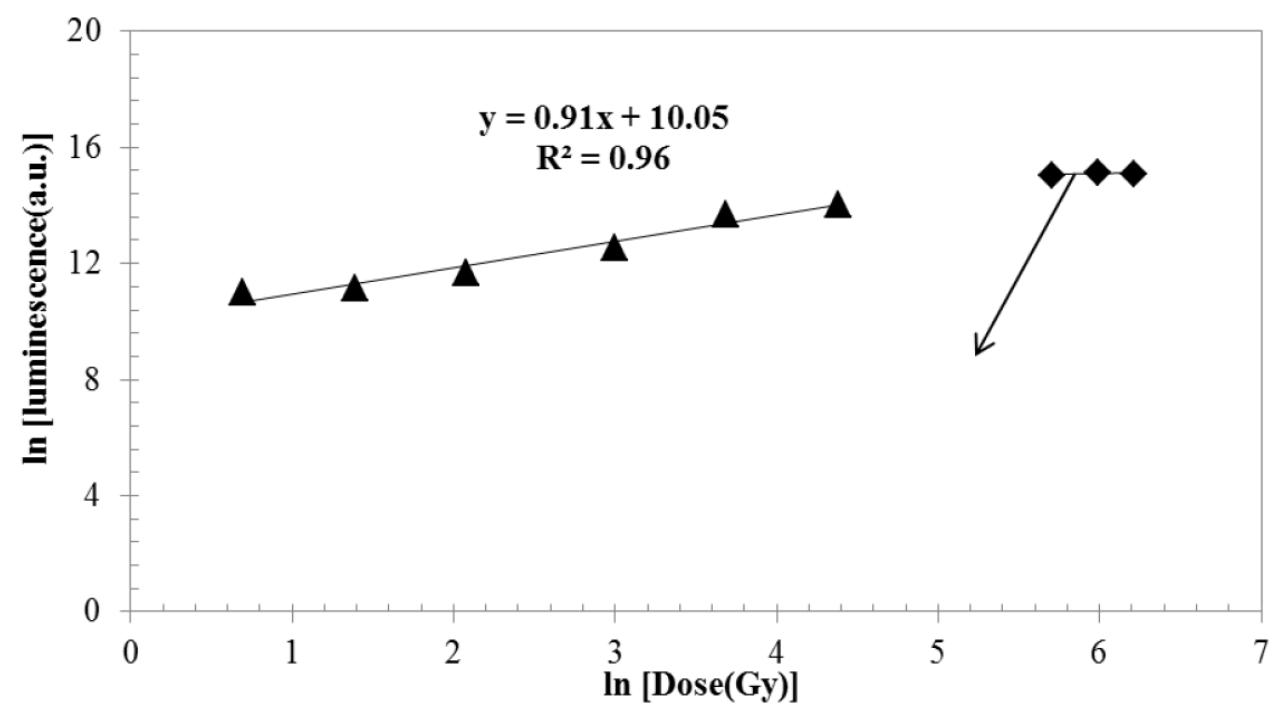

Fig. 3. The IRSL dose response curve (on graph, $y$ and $x$ represent IRSL and dose, respectively)

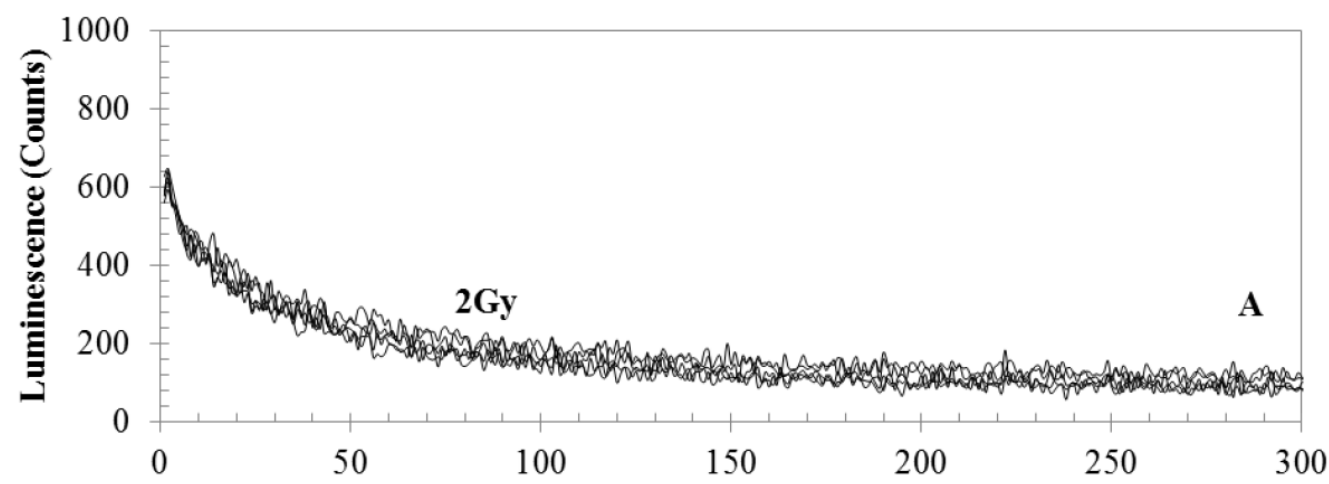

Stimulation time (s)

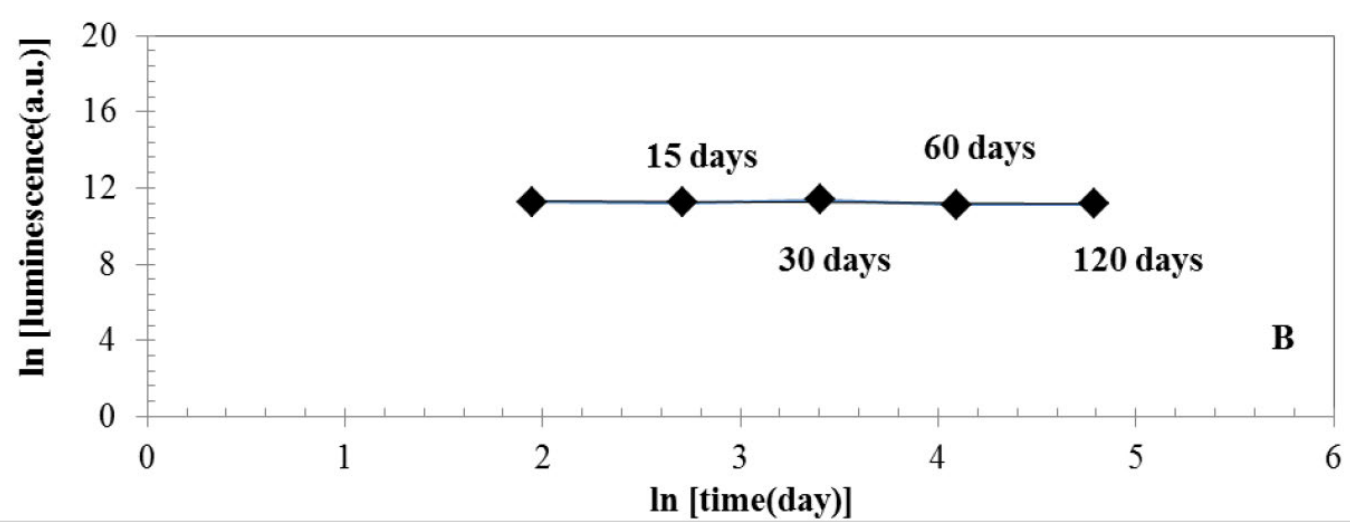

Fig. 4. (a) IRSL decay curves, irradiated 2 Gy and stored 1 week, 2 weeks, 1 month, 2 months, 4 months. (b) IRSL light sums after storage for the times shown. 

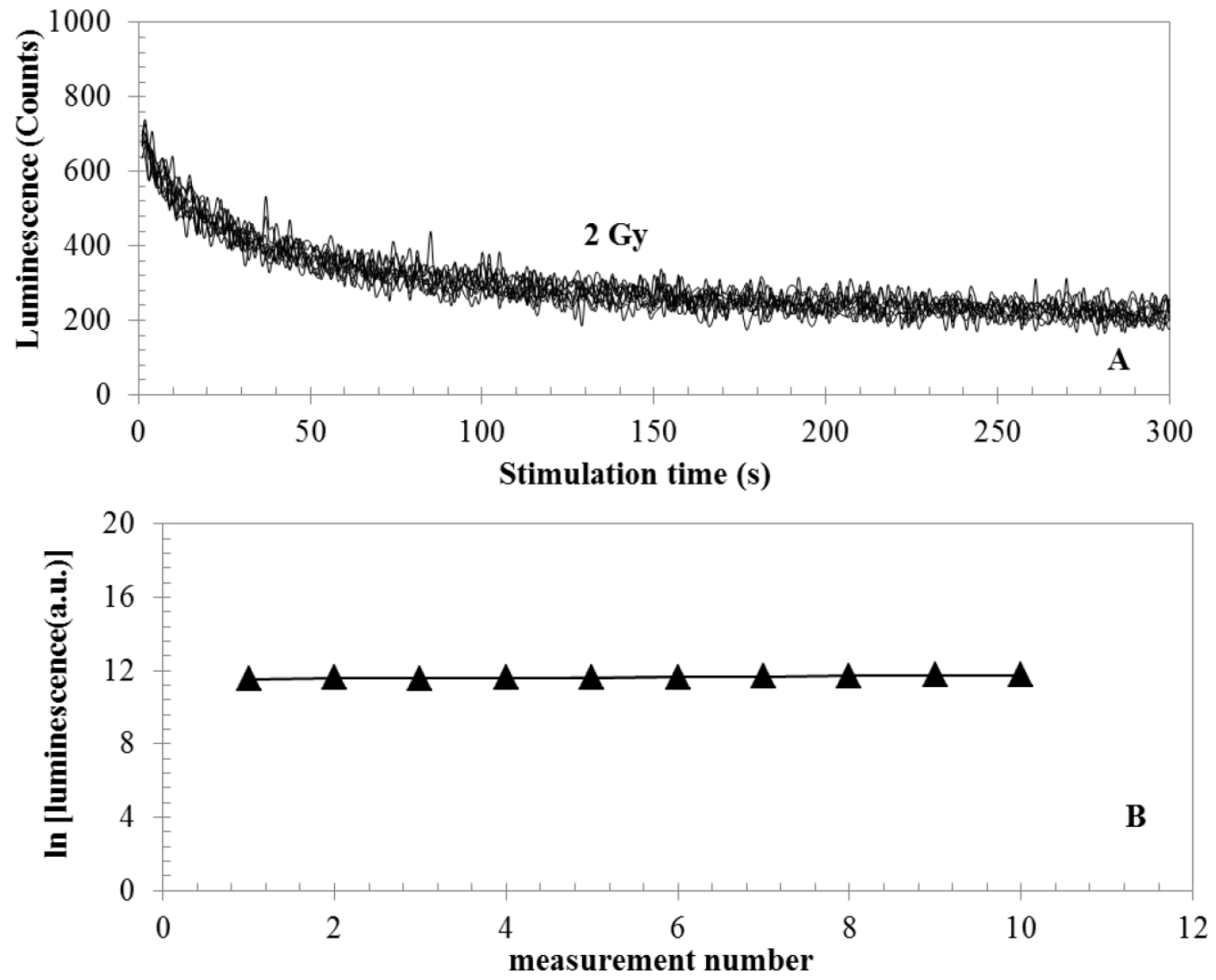

Fig. 5. Reproducibility of the IRSL measurement: (a) decay curves and (b) IRSL light sums, plotted as a function of the measurement number.

Table 1. XRF results of the natural aluminum corrosion. $A C$ - Aluminium Corrosion.

\begin{tabular}{|c|c|c|c|c|c|c|c|c|c|c|c|c|c|c|}
\hline $\begin{array}{l}\text { Element } \\
\text { AC (\%) }\end{array}$ & $\begin{array}{c}\mathrm{Na}_{2} \mathrm{O} \\
0.11\end{array}$ & $\begin{array}{l}\mathrm{MgO} \\
0.47\end{array}$ & $\begin{array}{l}\mathrm{Al}_{2} \mathrm{O}_{3} \\
24.11\end{array}$ & $\begin{array}{c}\mathrm{SiO}_{2} \\
43.05\end{array}$ & $\begin{array}{c}\mathrm{P}_{2} \mathrm{O}_{5} \\
0.38\end{array}$ & $\begin{array}{l}\mathrm{K}_{2} \mathrm{O} \\
0.81\end{array}$ & $\begin{array}{l}\mathrm{CaO} \\
15.41\end{array}$ & $\begin{array}{l}\mathrm{Ti}_{2} \mathrm{O} \\
0.29\end{array}$ & $\begin{array}{l}\mathrm{MnO} \\
0.05\end{array}$ & $\begin{array}{c}\mathrm{Fe}_{2} \mathrm{O}_{3} \\
4.4\end{array}$ & $\begin{array}{c}V \\
0.004\end{array}$ & $\begin{array}{c}\mathrm{Cr} \\
0.05\end{array}$ & $\begin{array}{c}S \\
0.53\end{array}$ & $\begin{array}{c}\mathrm{Cl} \\
0.06\end{array}$ \\
\hline Element & Co & $\mathrm{Ni}$ & $\mathrm{Cu}$ & $\mathrm{Zn}$ & $\mathrm{Ta}$ & W & $\mathrm{Hg}$ & $\mathrm{Tl}$ & $\mathrm{Pb}$ & U & $\mathrm{Ga}$ & $\mathrm{Ge}$ & As & $\mathrm{Se}$ \\
\hline $\mathrm{AC}(\mathrm{ppm})$ & 67.2 & 71.3 & 3689 & 15590 & 61 & 47 & 2 & 2.7 & 265.8 & 9.2 & 4 & 1.8 & 45.1 & 1.4 \\
\hline Element & $\mathrm{Br}$ & $\mathrm{Rb}$ & $\mathrm{Sr}$ & $\bar{Y}$ & $\mathrm{Zr}$ & $\mathrm{Nb}$ & Mo & $\mathrm{Cd}$ & $\ln$ & Sn & $\mathrm{Sb}$ & $\mathrm{Te}$ & I & Cs \\
\hline $\mathrm{AC}(\mathrm{ppm})$ & 4.9 & 24.9 & 416.8 & 8.4 & 684 & 4.8 & 11.8 & 1.8 & 2 & 59.9 & 18.1 & 2.9 & 5.6 & 12.9 \\
\hline Element & $\mathrm{Ba}$ & $\mathrm{La}$ & $\mathrm{Ce}$ & $\mathrm{Hf}$ & $\mathrm{Bi}$ & Th & & & & & & & & \\
\hline $\mathrm{AC}(\mathrm{ppm})$ & 726 & 24 & 27 & 49 & 2.8 & 1.9 & & & & & & & & \\
\hline
\end{tabular}

structures (Bøtter-Jensen et al., 2003). On the other hand, we can see that material contains different oxides, especially the $\sim 24 \% \mathrm{Al}_{2} \mathrm{O}_{3}$ and $\sim 43 \% \mathrm{SiO}_{2} . \mathrm{Al}_{2} \mathrm{O}_{3}$ is routinely used dosimetric applications, and the OSL dosimetric properties of $\mathrm{Al}_{2} \mathrm{O}_{3}: \mathrm{C}$ are well established (Akselrod et al., 1998 and Truscott et al., 2000). Another well-known luminescence material is $\mathrm{SiO}_{2}$ which is also routinely used for such dosimetric applications (Bøtter-Jensen et $a l ., 2003)$. We suspected these oxides and variety of elements can affect luminescence in the material.

The crystalline structure characteristics of the aluminum corrosion powders were investigated by X-ray diffraction (XRD) which were carried out in the $2 \theta=0^{\circ}-120^{\circ}$ as shown in Fig. 6. According to the results, two obvious diffraction peaks can be seen at $2 \theta=30.5^{\circ}$ and $33.7^{\circ}$. However, we cannot match these peaks with any known phases but those peaks indicate that the corrosion product has a crystalline structure which is consistent with the requirements of basic luminescence theory.

\section{CONCLUSION}

The optical stability and linearity of the IRSL signals of natural corrosion, for samples obtained from aluminum water pipes, were investigated in the present work. The results indicate that during the corrosion process a crys- 


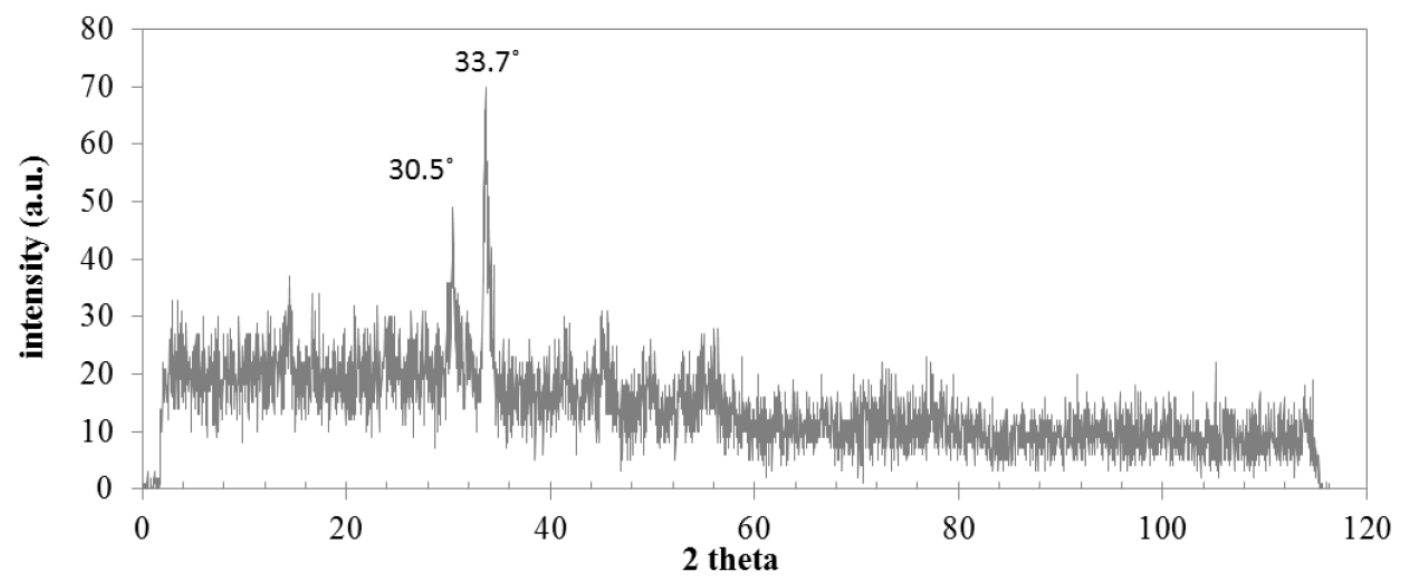

Fig. 6. XRD pattern of natural aluminum corrosion

talline structure is formed that contains some type of luminescence centers and traps and acts as a dosimeter. These traps show long-term stability during storage at the room temperature (over 4 months for aluminum corrosion). It has been demonstrated that the IRSL dose response of this material is approximately linear for doses in the range of 2-80 Gy and saturated by a $300 \mathrm{~Gy}$. The observed features suggest that aluminum corrosion can be used as a dosimeter for retrospective dose assessments in the dose range of 2-200 Gy.

The corroded surface was continually exposed to radiation from the surrounding which causes pre-dose. At the moment of the accident or even afterwards, pre-dose can be negligible near the accident dose. So this material can give us the information about the exposed dose.

Improvements in sensitivity may be necessary in order to be able of applying this technique to different aluminum and metal corrosion. These preliminary results indicate that aluminum corrosion may be a promising candidate for radiation measurements, environmental and retrospective dosimetries. We believe that this study can contribute to dosimeter investigations in particular with regard to the efforts of finding new and widely available materials for accident dosimetry.

\section{ACKNOWLEDGMENTS}

We would like to thank Prof. Dr. Yusuf Kağan Kadıoglu from Ankara University for XRD and XRF analyses and Prof. Dr. Shipu Chen and Dr. Ning Yu from Shanghai Jiao Tong University for his constructive comments.

This work was supported by the Scientific and Technical Research Council of Turkey (TUBITAK).

\section{REFERENCES}

Akselrod MS, Lucas AC, Polf JC and McKeever SWS, 1998. Optically stimulated luminescence of $\mathrm{Al}_{2} \mathrm{O}_{3}$. Radiation Measurements 29(34): 391-399, DOI 10.1016/S1350-4487(98)00061-4.

Bøtter-Jensen L and Murray AS, 2001. Optically stimulated luminescence techniques in retrospective dosimetry. Radiation Physics and Chemistry 61(3-6): 181-190, DOI 10.1016/S0969806X(01)00239-0.

Bøtter-Jensen L, McKeever SWS and Wintle AG, 2003. Optically Stimulated Luminescence Dosimetry. Elsevier, Amsterdam, ISBN:0-444-50684-5, $355 \mathrm{pp}$.

Göksu HY, Bailiff IK, Bøtter-Jensen L, Brodski L, Hütt G and Stoneham D, 1995. Interlaboratory beta source calibration using TL and OSL on natural quartz. Radiation Measurements 24(3): 479-483, DOI 10.1016/1350-4487(95)00258-G.

Göksu HY, Bailiff IK and Mikhailik VB, 2003. New approaches to retrospective dosimetry using cementitious building materials. $\mathrm{Ra}$ diation Measurments 37(4-5): 323-327, DOI 10.1016/S13504487(03)00005-2.

Göksu HY, 2003. Telephone chip-cards as individual dosemeters. Radiation Measurements 37(6): 617-620, DOI 10.1016/S13504487(03)00082-9.

McKeever SWS, 2001. Optically stimulated luminescence dosimetry. Nuclear Instruments and Methods B in Physics Research Section 184(1-2): 29-54, DOI 10.1016/S0168-583X(01)00588-2.

Meriç N, Kosal M, Atlıhan MA and Yüce ÜR, 2008. OSL properties of anthropological bone and tooth. Radiation Physics and Chemistry 77(6): 685-689, DOI 10.1016/j.radphyschem.2008.01.006.

Yüce UR, Meriç N, Atakol O and Yaşar F, 2010. Dose response of hydrazine- deproteinated tooth enamel under blue light stimulation. Radiation Measurements, 45(7): 797-800, DOI 10.1016/j.radmeas.2010.03.005.

Nisancioglu K, 1992. Corrosion of aluminium alloys. Proceedings of ICAA3, vol 3, pp 239-259. Trondheim, NTH and SINTEF.

Pourbaix M, 1974. Atlas of electrochemical equilibria in aqueous solutions, NACE Cebelcor, Huston, 644 pp.

Spooner NA, Aitken MJ, Smith BW, Franks M and McElroy C, 1990. Archaeological dating by infrared-stimulated luminescence using a diode array. Radiation Protection Dosimetry 34(1-4): 83-86.

Truscott AJ, Duller GAT, Bøtter-Jensen L, Murray AS and Wintle AG, 2000. Reproducibility of optically stimulated luminescence measurements from single grains of $\mathrm{Al}_{2} \mathrm{O}_{3}: \mathrm{C}$ and annealed quartz. $R a$ diation Measurements 32(5-6), 447-451, DOI 10.1016/S13504487(00)00080-9.

Yukihara EG, Mittani J, McKeever SWS and Simon SL, 2007. Optically Stimulated Luminescence (OSL) of dental enamel for retrospective assessment of radiation exposure. Radiation Measurements 42(6-7), 1256-1260, DOI 10.1016/j.radmeas.2007.05.038. 